\title{
Hypertension care cascade in Chile: a serial cross-sectional study of national health surveys 2003-2010-2017
}

Álvaro Passi-Solar ${ }^{1,2}$, Paula Margozzini ${ }^{2 *}$, Jennifer S. Mindell ${ }^{1}$, Milagros Ruiz ${ }^{1}$, Carlos A. Valencia-Hernandez ${ }^{1}$ and Shaun Scholes ${ }^{1}$

\begin{abstract}
Background: Trend data on hypertension prevalence and attainment indicators at each step of the care cascade (awareness, treatment, control) are required in Chile. This study aims to quantify trends (2003-2017) in prevalence and in the proportion of individuals with hypertension attaining each step of the care cascade among adults aged 17 years or older, and to assess the impact of lowering the blood pressure (BP) thresholds used to define elevated $\mathrm{BP}$ on these indicators.
\end{abstract}

Methods: We used data from 2003, 2010, and 2017 Chilean national health surveys. Each year we assessed levels of (1) mean systolic (SBP) and diastolic (DBP) blood pressure, (2) hypertension prevalence (BP $\geq 140 / 90 \mathrm{mmHg}$ or use of antihypertensive treatment), and (3) awareness, treatment, and control. Logistic regression on pooled data was used to assess trends in binary outcomes; linear regression was used to assess trends in continuous SBP and DBP. We compared levels of hypertension prevalence using two sources to ascertain antihypertensive treatment (selfreported versus medicine inventory). The 2017 American College of Cardiology/American Heart Association (ACC/ AHA) guidelines were used to re-define hypertension using lower thresholds ( $B P \geq 130 / 80 \mathrm{mmHg}$ ).

Results: Hypertension prevalence was 34.0, 32.0 and 30.8\% in 2003, 2010 and 2017, respectively. Levels of treatedand controlled-hypertension were significantly higher in 2017 than in 2003 (65\% versus 41\% for treatment, $P<$ $0.001 ; 34 \%$ versus $14 \%$ for control, $P<0.001$ ), while levels of awareness were stable (66\% versus $59 \%, P=0.130$ ). Awareness, treatment, and control levels were higher among females in 2003, 2010, and 2017 ( $P<0.001)$. Mean SBP and DBP decreased over the 15-year period, except for SBP among females on treatment. Adopting the $2017 \mathrm{ACC} /$ AHA guidelines would increase hypertension prevalence by 17 and 55\% in absolute and relative terms, respectively. Conclusions: Chile has experienced a positive population-wide lowering in blood pressure distribution which may be explained partly by a significant rise in levels of treated-and controlled-hypertension since 2003. Lowering the thresholds used to define elevated BP would substantially increase the financial public health challenge of further improving attainment levels at each step of the care cascade. Innovative and collaborative strategies are needed to improve hypertension management, especially among males.

Keywords: Chile, Hypertension, Blood pressure, Care cascade, Management, Awareness, Antihypertensive treatment, Health surveys, Guidelines

\footnotetext{
* Correspondence: pmargoz@med.puc.cl

${ }^{2}$ Department of Public Health, School of Medicine, Pontificia Universidad Católica de Chile, Diagonal Paraguay 362, CP 88330077 Santiago, Chile

Full list of author information is available at the end of the article
}

(c) The Author(s). 2020 Open Access This article is licensed under a Creative Commons Attribution 4.0 International License, which permits use, sharing, adaptation, distribution and reproduction in any medium or format, as long as you give appropriate credit to the original author(s) and the source, provide a link to the Creative Commons licence, and indicate if changes were made. The images or other third party material in this article are included in the article's Creative Commons licence, unless indicated otherwise in a credit line to the material. If material is not included in the article's Creative Commons licence and your intended use is not permitted by statutory regulation or exceeds the permitted use, you will need to obtain permission directly from the copyright holder. To view a copy of this licence, visit http://creativecommons.org/licenses/by/4.0/ The Creative Commons Public Domain Dedication waiver (http://creativecommons.org/publicdomain/zero/1.0/) applies to the data made available in this article, unless otherwise stated in a credit line to the data. 


\section{Background}

Hypertension continues to be one of the most important health challenges, being a major risk factor for cardiovascular morbidity and mortality worldwide. Low and middle-income countries (LMICs) are showing the sharpest increase in the prevalence of hypertension globally during the last four decades [1], explained only partially by population ageing. LMICs also show lower levels of attainment at each step of the hypertension care cascade, compared with highincome countries (HICs) [2]. In Chile, cardiovascular diseases (CVD) are the main cause of death, explaining $26-27 \%$ of the overall mortality every year between 2000 and 2017 [3]. Chile, a country of 18.7 million inhabitants with $11.4 \%$ aged 64 years and over and with $37.4 \%$ living in the Metropolitan region (Santiago), has currently one of the most prosperous economies in Latin America (ranked as a HIC since 2012) but at the same time has a very low level of health expenditure (8.9\% of GDP) [4]. Furthermore, this economic prosperity has not been shared equally across all segments of the population, creating a unique profile for hypertension prevalence and its care cascade (i.e. the proportion of persons with hypertension at various stages of the management continuum that starts with screening and ends with control).

Chile has a very strong and efficient high coverage public-health care system bringing success in indicators of maternal and infant health. Sustained efforts have been made to provide care to the hypertensive population since the 1980s [5] through its Mixed Healthcare system (public and private), with $85 \%$ of the population using public-health insurance and services in 2015 [6]. Since the 1980s, two major health system interventions were introduced to improve the management of hypertension. First, in 2002, the former hypertension disease specific programme in primary public care was transformed into an integrated risk-stratified based model: the "Cardiovascular Health Program" and second, in 2005, a law was passed (Garantías Explícitas en Salud [GES]) which warranted timely access and financial coverage (e.g. medicines free-of-charge) to all insured Chileans (public and private) for the most prevalent chronic diseases, including hypertension [7]. These efforts are aligned with the current health goals for 2010 to 2020 of increasing the level of controlled hypertension $(\mathrm{BP}<140 / 90 \mathrm{mmHg}$ ) in relative terms by $50 \%$ [8].

While hypertension prevalence (defined as BP $\geq 140 / 90$ $\mathrm{mmHg}$ or use of antihypertensive treatment) across 90 countries remained stable between 2000 and 2010 at around 30\%, key hypertension care cascade indicators awareness, treatment and control - increased slightly from 41 to $47 \%$; 32 to $37 \%$; and 34 to $37 \%$ respectively [2].
Despite the availability of highly effective antihypertensive medications, the majority of hypertensive patients on treatment do not therefore achieve BP control [2].

Hypertension prevalence, and levels of uncontrolled hypertension, would be even higher if a stricter definition of hypertension based on lower thresholds for defining elevated BP is adopted. According to the 2017 American College of Cardiology/American Heart Association guidelines (2017 ACC/AHA) [9], the commonly used (seventh Joint National Committee [JNC] 7) [10] threshold for high $\mathrm{BP}(\mathrm{BP} \geq 140 / 90 \mathrm{mmHg})$ should be lowered to $\mathrm{BP} \geq 130 / 80 \mathrm{mmHg}$. This change in criteria calls for a more aggressive approach in order to decrease the risk of CVD events occurring at lower levels of BP. The recommendation to lower BP thresholds was prompted by the findings of SPRINT (Systolic Blood Pressure Intervention Trial) which found significant reductions in the primary composite outcome (myocardial infarction, other acute coronary syndromes, stroke, heart failure, or death from cardiovascular causes) and in overall mortality among adults in the intensive treatment group (BP target $<120 \mathrm{mmHg}$ ) versus those in the standard treatment group (BP target $<140 \mathrm{mmHg}$ ) [11].

Attainment of care cascade indicators for various diseases have been recently described for LMICs [12] and for HICs [13] using cross-sectional nationally representative health examination surveys, based on the JNC 7 definition of hypertension (BP $\geq 140 / 90 \mathrm{mmHg}$ or use of antihypertensive treatment). Geldsetzer et al. showed a prevalence of hypertension of around 30\% for most Latin American and Caribbean countries, with the lowest prevalence in Ecuador (9\%) and the highest in Grenada (41\%); however, levels were not directly comparable due to differences in age [12]. Zhou B et al. showed higher levels of hypertension for HICs than for most LMICs, with values amongst those aged 40-79 years ranging between 33\% in Australia to over 52\% in Finland [13].

Recent cross-sectional analysis of Latin American data collected as part of the Prospective Urban Rural Epidemiology (PURE) study was based on 33,276 participants aged 35-70 years from urban and rural communities in six countries (Argentina, Brazil, Chile, Colombia, Peru and Uruguay). The study by Lemelas et al. reported significant variations in prevalence (18$52 \%)$, awareness $(52-65 \%)$, treatment $(47-63 \%)$ and control (16-30\%) [14]. However, the analytical sample was not nationally representative, and its cross-sectional design meant that no evidence could be provided on trends in these indicators over time.

There is scarce evidence of recent trends in the hypertension care cascade from countries such as Chile that have experienced fast epidemiologic transitions. To the best of our knowledge, no studies to date in the Latin American and Caribbean region (LAC) have quantified 
these trends using nationally representative, measured BP data, and only one study (in Peru) has assessed the implications of lowering the $\mathrm{BP}$ thresholds in line with the 2017 ACC/AHA guidelines (albeit using an indicator of high BP alone) $[15,16]$. Using data from three nationally representative Chilean health examination surveys covering a 15 -year period $(2003 ; 2010 ; 2017)$, the aims of the present study were to: (1) quantify trends in hypertension prevalence and in attainment at each step of its care cascade (i.e. awareness, treatment and control), including an assessment of gender disparities; and (2) quantify the impact of lowering the BP thresholds on these indicators.

\section{Methods}

\section{Study design and setting}

We used data from the three most recent Chilean National Health Surveys (Encuesta Nacional de Salud, ENS: 2003; 2010; 2017). The 2003 ENS sample was stratified with a random sub-sample selected from participants of the Quality of Life and Health Survey [17]. The sampling frame for the Quality of Life and Health Survey was household information from the National Census of 1992, and sampling was carried out by a stratified, cluster design. The subsample of participants for the ENS 2003 was selected using the same age-gender-region structure of the original sample frame, except for the oversampling of one region. Fresh samples were selected for the 2010 and 2017 surveys based on stratified cluster sampling. Sampling for both was based on the master sample frame of the Chilean National Institute of Statistics and the Population and Housing Census of Chile.

The target population for each survey was the freeliving general population aged 17 years or older (2003) and aged 15 years or older (2010 and 2017). Institutionalised and non-Spanish speaking individuals were excluded. Persons aged 65 years or over were oversampled. One eligible person was randomly selected for interview within the selected household using a Kish grid [18]. ENS survey instruments and protocols are described in detail elsewhere [19].

\section{Ethics approval and consent to participate}

The study protocol and ethical consent forms were approved by the ethics committee of the Pontificia Universidad Católica de Chile (PUC) and the Chilean Ministry of Health (ENS 2003: number could not be retrieved; 2010: 09-113; 2017: 16-019). Persons selected for inclusion provided informed and signed consent before participation.

\section{Data collection}

Data collection procedures were generally similar across the three surveys. In the first home visit, a trained interviewer applied health questionnaires faceto-face, including the following questions regarding hypertension awareness: "Have you ever been told by a doctor, nurse or health care provider that you have high blood pressure?" and hypertension treatment (regardless of awareness) "Are you currently carrying or doing any program or treatment indicated by a health professional to keep your blood pressure under control?". Participants reporting that they were on treatment were asked about type of treatment (response options: medications, treatment without medication, or both). During the second visit, a trained nurse measured $\mathrm{BP}$ and recorded the medications participants were currently using (prescribed or not) via a detailed inventory. Medications were classified using the anatomical therapeutic chemical (ATC) classification system [20]. Sitting BP was measured after a five-minute rest using an upper arm monitor (Omron, Healthcare Co Ltd., Kyoto, Japan: models HEM713C, HEM742 and HEM7200 in 2003, 2010 and 2017, respectively) with appropriately sized arm cuffs, with a two-minute pause between readings. Two BP readings were taken in 2003 while three readings were taken in 2010 and 2017. To ensure like-for-like comparisons, we used the average of the first- and second-readings in each year. We decided at the outset of the present study that this approach would provide the most accurate estimate of change in hypertension across the three surveys giving more value to the reproducibility of the results to estimate trends over time [21].

\section{Definitions of hypertension and the care cascade}

Estimates of hypertension prevalence vary by choice of high BP cut-points [9]. We compared two different definitions of hypertension. First, we identified participants with hypertension based on the seventh report of the JNC on prevention, detection, evaluation and treatment of high blood pressure: SBP/DBP $\geq 140 / 90$ $\mathrm{mmHg}$ or current use of antihypertensive treatment (hereafter referred to as the JNC 7 guideline) [10]. Second, we identified participants with hypertension based on the 2017 ACC/AHA guidelines: SBP/DBP $\geq 130 / 80 \mathrm{mmHg}$ or current use of antihypertensive treatment [9].

We focused on three steps of the hypertension care cascade: awareness, treatment, and control. Among those classified as hypertensive, we defined: (1) awareness as the report of prior diagnosis of high BP by a healthcare professional; (2) treatment (in our main analyses) as the current use of antihypertensive medication as identified in the medicine inventory (ATC codes: C02, C03, C07, C08, C09); and (3) control according to the JNC $7(\mathrm{BP}<140 / 90 \mathrm{mmHg})$ and the $2017 \mathrm{ACC} / \mathrm{AHA}$ $(\mathrm{BP}<130 / 80 \mathrm{mmHg})$ guidelines. 


\section{Sociodemographic characteristics}

Participants were grouped into six age categories (17$34 ; 35-44 ; 45-54 ; 55-64 ; 65-74 ; 75+)$. Educational status based on years of formal education was grouped as low (<8 years); medium ( $8-12$ years) and high $(>12$ years); place of residence was grouped as urban or rural.

\section{Statistical analysis}

Analyses were restricted to adults aged 17 years or over to ensure comparability across the three surveys. First, we summarised the sociodemographic profile (age; gender; educational level; place of residence) and estimated average SBP/DBP levels in each survey amongst all participants with valid BP and medicine data.

Second, amongst those classified as hypertensive (JNC 7 guideline), we calculated the levels of awareness, treatment and control. Third, pooling data across years, we used age-adjusted logistic regression to estimate the gender-specific trends in hypertension (JNC 7 guideline). Among those classified as hypertensive, we used ageadjusted logistic regression to calculate gender-specific trends in awareness, treatment, and control. In each analysis survey year and age were entered into the models as a three-category independent variable and as a single continuous variable, respectively. Results were summarised using Odds Ratios (ORs) with accompanying 95\% confidence intervals (95\% CI). Pairwise comparisons were used to evaluate change over time (i.e. 2010 versus 2003; 2017 versus 2003; and 2017 versus 2010). Ageadjusted linear regression models were used to test for significant trends in mean SBP and DBP (regardless of treatment and separately by treatment status).

Fourth, we quantified the difference in hypertension prevalence and in levels of awareness, treatment and control between the current (JNC 7) and new (2017 ACC/AHA) guidelines. For each survey year, participants were classified into one of four mutually exclusive groups. According to the JNC 7 guidelines, these groups were defined as follows: normotensive $(<140 / 90 \mathrm{mmHg})$; treated and controlled $(<140 / 90 \mathrm{mmHg})$; treated, but uncontrolled ( $\geq 140 / 90 \mathrm{mmHg})$; and untreated and uncontrolled ( $\geq 140 / 90 \mathrm{mmHg}$ ). The corresponding classification using the 2017 ACC/AHA guidelines was as follows: normotensive $(<130 / 80 \mathrm{mmHg})$; treated and controlled $(<130 / 80 \mathrm{mmHg})$; treated, but uncontrolled $(\geq 130 / 80 \mathrm{mmHg})$, and untreated and uncontrolled $(\geq 130 / 80 \mathrm{mmHg})$. Applying the 2017 Chilean census data to the ENS 2017 [22], we estimated the number of additional adults who would be eligible for antihypertensive treatment based on the 2017 ACC/AHA guidelines.

\section{Sensitivity analysis}

In our main analysis, ascertaining use of antihypertensive treatment through ATC codes may slightly overestimate prevalence as some medicines can be used for other conditions without the co-existence of hypertension. To determine the robustness of our ascertainment of antihypertensive treatment, we estimated hypertension prevalence based on the JNC 7 guidelines using selfreported treatment and compared the difference between the two sets of estimates (i.e. self-report versus ATC codes collected via the detailed medicine inventory). In a second sensitivity analysis we estimated the change in hypertension prevalence using the average of the second and third BP readings in the 2010 and 2017 surveys.

Analyses were based on complete-cases and were weighted accounting for differences in selection probability (e.g. selection of one person per household) and non-response rates. $P$-values $<0.05$ were classified as statistically significant (two-tailed). All analyses were conducted in Stata V14.0 (StataCorp LP, College Station, Texas, U.S.) adjusting for the complex survey design.

\section{Results \\ Sample characteristics}

Response rates for the total sample were 63, 75 and 67\% in 2003, 2010 and 2017 respectively. Overall, 3614, 5267 and 6074 adults took part in the ENS 2003, 2010, and 2017 surveys, respectively. Of these, 3448 (95\%), 4863 (92\%) and 5379 (86\%) adults took part in the nurse visit; the vast majority of these (99\%) had valid BP and medicine data. Table 1 shows the sociodemographic profile and average levels of BP in each survey year amongst the 13,605 participants aged 17 years or over with valid BP and medicine data. Characteristics were similar across the three surveys, with the exception of an increase over time in the proportion of participants in the highest educational group ( $>12$ years of formal education).

\section{Hypertension and its care cascade (awareness, treatment and control)}

Based on the (current) JNC 7 guidelines (SBP/DBP $\geq 140 / 90 \mathrm{mmHg}$ or current use of antihypertensive treatment), Fig. 1 shows the levels of hypertension and levels of attainment at each care cascade step (awareness, treatment, and control) across the three surveys. The estimates and accompanying 95\% confidence intervals (95\% CI) are provided as supplementary data (Additional file 1: Table S1). For brevity, we report here on the change between the first- and last-surveys (i.e. 2003 and 2017). Among all adults, hypertension prevalence decreased slightly from $34.0 \%$ (95\% CI: 31.6-36.4\%) to 30.8\% (95\% CI: 28.7-32.9\%). Hypertension prevalence decreased among males from 37.1\% (95\% CI: 33.5$40.9 \%)$ to $31.2 \%$ (95\% CI: $28.1-34.5 \%)$ and decreased among females from $31.0 \%$ (95\% CI: $28.0-34.1 \%)$ to 30.3\% (95\% CI: 27.6-33.1\%). 
Table 1 Sociodemographic characteristics by survey year. Chile ENS2003-2010-2017

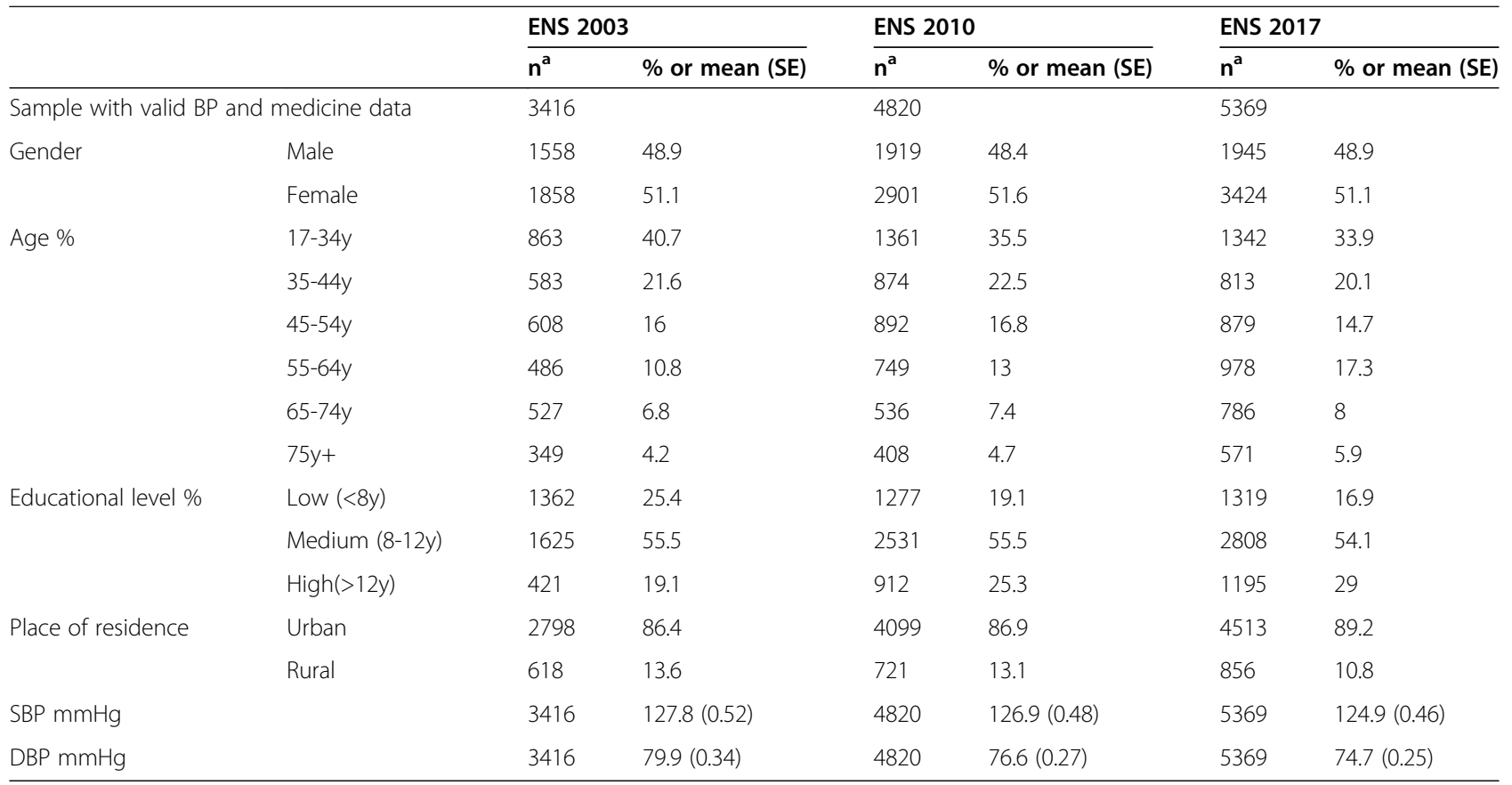

Estimates are weighted for the complex survey design

ENS Encuesta Nacional de Salud, Chilean National Health Survey, BP Blood pressure, SBP Systolic BP, DBP Diastolic BP, SE Standard error

a Unweighted sample size. Column \%'s shown for sociodemographic characteristics

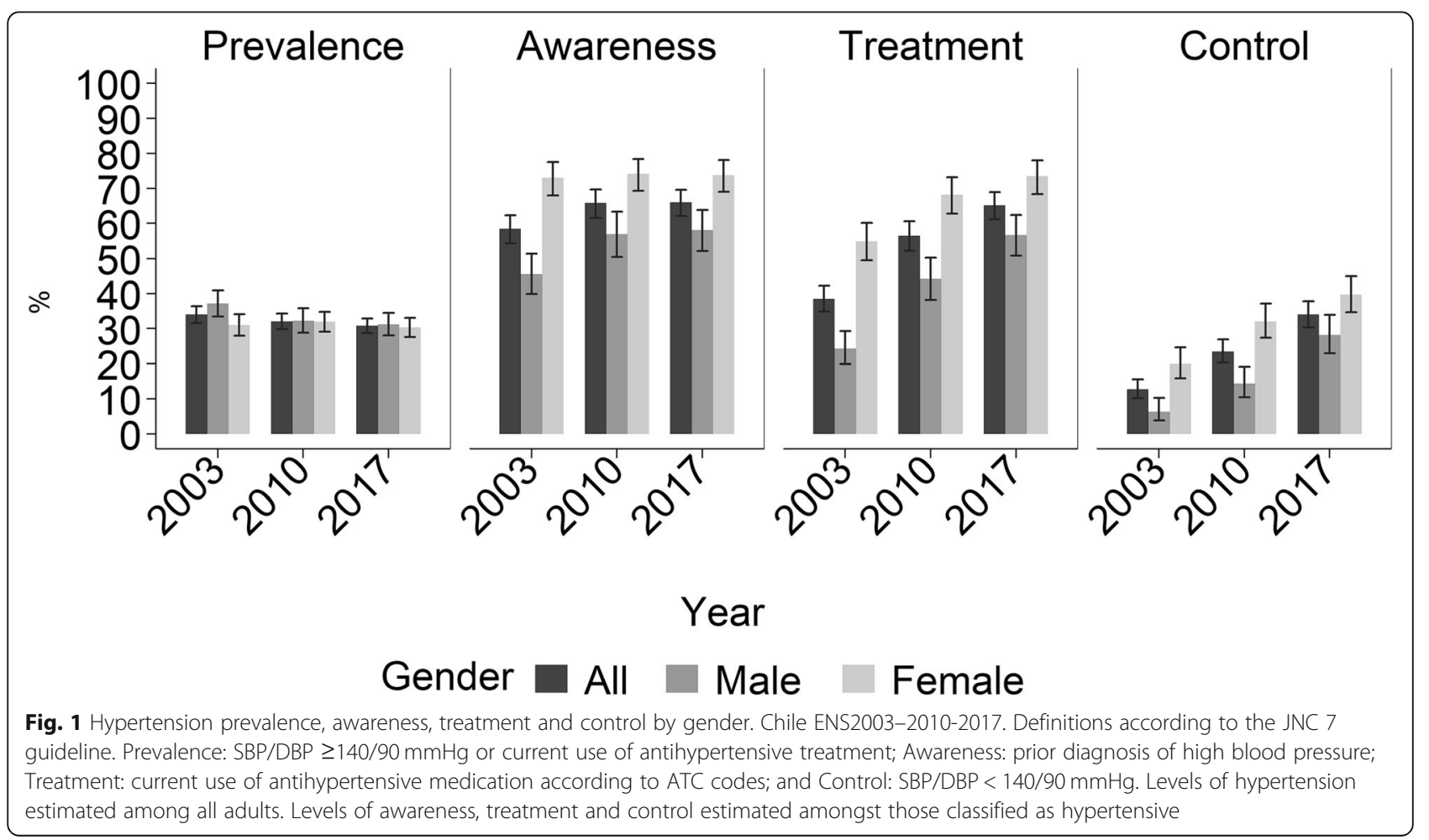


Among those classified as hypertensive, attainment at each cascade step mainly showed improvement. Levels of treated- and controlled-hypertension were significantly higher in 2017 than in 2003 (65\% versus 41\% for treatment, $P<0.001 ; 34 \%$ versus $14 \%$ for control, $P<$ $0.001)$, while levels of awareness were stable (66\% versus 59\%, $P=0.130$ ) (Fig. 1; Additional file 1: Table S1). Trends were similar by gender. First, levels of awareness among males increased from 45.6\% (95\% CI: 39.9$51.4 \%$ ) to $58.1 \%$ (95\% CI: $52.2-63.8 \%$ ); levels were higher among females but remained stable at around $73 \%$. Second, levels of treatment among males increased from 24.3\% (95\% CI: $19.9-29.3 \%$ ) to $56.7 \%$ (95\% CI: $50.9-$ $62.4 \%)$ and increased among females from 54.9\% (95\% CI: $49.5-60.1 \%$ ) to $73.5 \%$ (95\% CI: $68.4-78.0 \%)$. Third, levels of controlled hypertension among males increased from $6.3 \%$ (95\% CI: $3.8-10.3 \%$ ) to $28.2 \%$ (95\% CI: $23.0-$ $33.9 \%)$ and increased among females from 19.9\% (95\% CI: $15.9-24.7 \%$ ) to $39.7 \%$ (95\% CI: $34.7-45.0 \%$ ).

\section{Age-adjusted trends in hypertension and its cascade of care}

Figure 2 shows the age-adjusted trends in hypertension and in attainment at each cascade step by gender based on logistic regression models. Estimates and accompanying 95\% CIs are provided as supplementary data (Additional file 1: Table S2). Among males, the odds of hypertension decreased significantly between 2003 and 2010 (OR: 0.63; 95\% CI: 0.48-0.83) and between 2010 and 2017 (OR: 0.77; 95\% CI: 0.59-1.00). The odds of hypertension decreased for females between 2010 and
2017 (OR: 0.73; 95\% CI: 0.57-0.92). In a pooled analysis, the odds of hypertension were significantly lower for females than for males (OR: 0.73; 95\% CI: 0.64-0.84, $P<$ 0.001) (Additional file 1: Table S3).

Amongst those classified as hypertensive, the odds of awareness did not change significantly over time, except among males, where the odds increased from 2003 to 2010 (OR: 1.45; 95\% CI: 1.02-2.06). Compared with 2003, the odds of treatment and control were significantly higher in 2010 and in 2017 for both genders (Fig. 2; Additional file 1: Table S2). In a pooled analysis, the age-adjusted odds of awareness (OR: 2.27; 95\% CI: 1.86-2.77, $P<0.001$ ), treatment (OR: 2.53 ; 95\% CI: $2.07-$ 3.09, $P<0.001$ ) and control (OR: 3.53; 95\% CI: 2.634.73, $P<0.001)$ were significantly higher for females than for males (Additional file 1: Table S3).

\section{Age-adjusted trends in SBP and DBP}

Average levels of age-adjusted SBP and DBP among all adults (i.e. regardless of treatment) decreased significantly over the 15-year period for both genders (Additional file 1: Table S4). For example, mean SBP decreased by $4.4 \mathrm{mmHg}$ (95\% CI: $2.9-6.0 \mathrm{mmHg}$ ) and by $5.8 \mathrm{mmHg}$ (95\% CI: 4.3-7.4 mmHg) between 2003 and 2017 among males and females, respectively.

Additional analyses stratified by treatment status showed that mean BP levels decreased significantly among all groups, with the exception of no significant change in mean SBP among females using antihypertensive treatment (Additional file 1: Table S4).

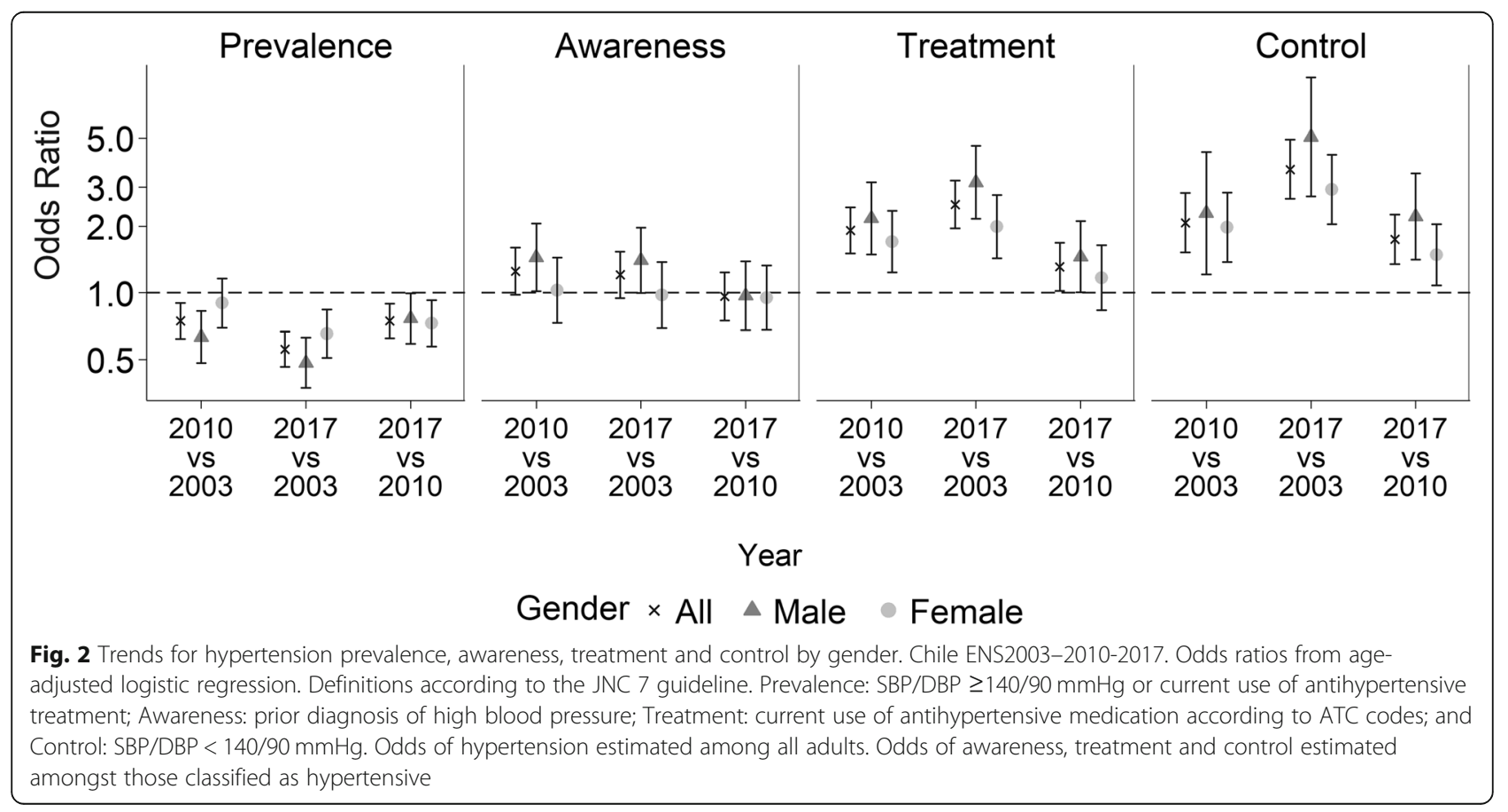




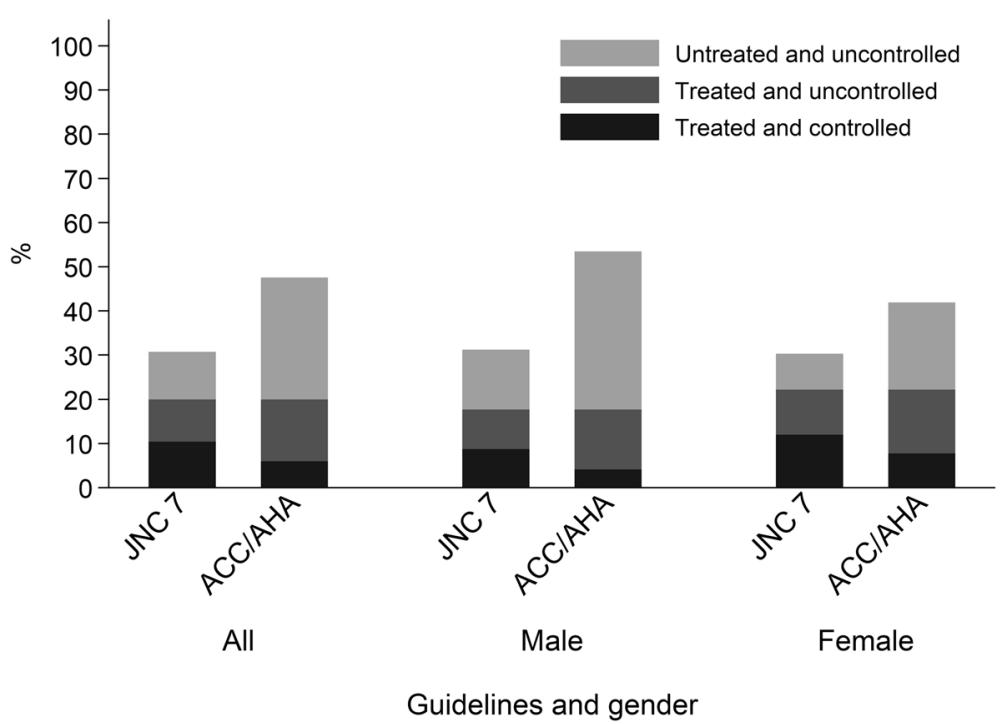

Fig. 3 Prevalence, treatment and control of hypertension according to JNC 7 and 2017 ACC/AHA guidelines by gender. Chile ENS2017. JNC 7 groups defined as follows: normotensive $(<140 / 90 \mathrm{mmHg})$; treated and controlled $(<140 / 90 \mathrm{mmHg})$; treated and uncontrolled $(\geq 140 / 90 \mathrm{mmHg})$; untreated and uncontrolled ( $\geq 140 / 90 \mathrm{mmHg}$ ). 2017 ACC/AHA groups defined as follows: normotensive $(<130 / 80 \mathrm{mmHg})$; treated and controlled $(<130 / 80 \mathrm{mmHg})$; treated and uncontrolled $(\geq 130 / 80 \mathrm{mmHg})$; untreated and uncontrolled $(\geq 130 / 80 \mathrm{mmHg})$. Use of antihypertensive treatment ascertained using ATC codes

\section{Hypertension prevalence based on lower BP thresholds} Based on the ENS 2017 data, Fig. 3 shows the difference in hypertension prevalence and in the proportion of adults attaining each step of the care cascade based on the new (2017 ACC/AHA) and current (JNC 7) guidelines. Estimates and accompanying 95\% CIs are provided as supplementary data (Additional file 1: Table S5). Overall, hypertension prevalence in 2017 would be about $17 \%$ percentage points higher in absolute terms if the BP threshold was lowered to $<130 / 80 \mathrm{mmHg}(2017 \mathrm{ACC} /$ AHA: 47.6, 95\% CI: 45.2-50.0\%; JNC 7: 30.7, 95\% CI: $28.7-32.9 \%$ ); a relative increase of around $55 \%$. Based on the 2017 census, we estimate that an additional 2.3 million adults aged 17 years or over would therefore be classified as hypertensive and so be eligible for antihypertensive treatment. We estimate that the proportion of adults in the population with uncontrolled and untreated hypertension in 2017 using the 2017 ACC/AHA guideline would be about $17 \%$ percentage points higher (2017 ACC/AHA: 27.5\%; 95\% CI: 25.429.8\%; JNC 7: 10.7\%; 95\% CI: 9.4-12.2\%); whilst the proportion of adults with treated, but uncontrolled hypertension would be about $4.4 \%$ percentage points higher (2017 ACC/AHA: 14.0\%; 95\% CI: 12.6-15.5\%; JNC 7: 9.6\%; 95\% CI: $8.5-10.8 \%)$.

\section{Sensitivity analysis}

Our sensitivity analysis showed similar levels of hypertension (based on the JNC 7 definition), whether using ATC-codes from the detailed nurse-administered medicine inventory or self-reported data to ascertain use of antihypertensive treatment. The absolute difference in the two sets of estimates (ATC versus self-reported) was $0.1,3.0$ and $1.2 \%$ in 2003, 2010 and 2017 respectively (Additional file 1: Figure S1). Repeating our main analyses using the average of the second- and third-BP readings in ENS 2010 and ENS 2017 produced similar evidence regarding trends over time. For example, the estimated OR for hypertension prevalence in 2017 versus 2003 slightly decreased from 0.56 (95\% CI: $0.46-0.67$ ) to 0.53 (95\% CI: $0.44-0.63$ ). The OR for awareness slightly increased from 1.20 (95\% CI: 0.94$1.53)$ to 1.27 (95\% CI: 0.99-1.63). The pattern was similar for treated- and controlled-hypertension. The OR for treatment increased from 2.49 (95\% CI: 1.953.20 ) to 2.73 (95\% CI: $2.11-3.52$ ); the OR for control increased from $6.85(4.69-10.02)$ to $7.58(5.18-11.08)$ (Additional file 1: Table S3).

\section{Discussion}

Data on current trends in hypertension prevalence and changes over time in the levels of attainment at each step of its care cascade (i.e. awareness, treatment and control) are required in the LAC region. Our analysis of Chilean health examination survey data indicates that around three-in-ten adults aged 17 years or older had hypertension (according to the JNC 7 guideline: $\mathrm{BP} \geq$ $140 / 90 \mathrm{mmHg}$ or use of antihypertensive treatment), with the prevalence from 2003 to 2017 showing a small but significant decline (from 37 to $31 \%$ for males; from 
31 to $30 \%$ for females). Mean SBP and DBP levels also decreased at the population level over the 15-year period.

\section{Explanations for observed trends}

Average BP levels fell steadily worldwide between 1975 and 2015 [1]. Some uncertainty exists about the drivers of the worldwide trends in average BP and hypertension prevalence, particularly as the reductions in BP levels have been accompanied by increases in a number of the leading risk factors for high $\mathrm{BP}$, including high body mass index (BMI) and diabetes [23]. Our results also showed decreases in average BP levels regardless of treatment status (with the exception of no significant change in mean SBP among females on treatment), while evidence from other studies analysing Chilean data over the same time period shows that levels of obesity have increased, whilst levels of physical inactivity were unchanged [24]. The decrease in BP can be explained at least partially by the increased detection of high BP by health care professionals (awareness) and by the subsequent wider uptake of antihypertensive treatments [1, 25]. Evidence consistently shows that higher levels of hypertension are associated with lower levels of income and formal education [26, 27]. Therefore, some of the BP decline in Chile could be attributed to the decrease in absolute poverty from 29 to $9 \%$ and the increase in the average length of time spent in formal education from 10 to 11 years between 2009 and 2017 [28]. The decline in hypertension prevalence in Chile was similar to that observed in other HICs, potentially driven by the decrease in risk factors which buffered the expected increase due to the rises in obesity and diabetes. For instance, salt intake [29] and exposure to dietary trans fatty acids and smoking decreased over time $[24,30]$. Since 2011, the average salt levels in bread has gradually reduced and stop signs were introduced in 2012 on packaged foods "high in" energy, sodium, sugars, and saturated fats, which contributed to a healthier food industry reformulation [31, 32]. Despite the progress over the 15-year period, the prevalence of hypertension (defined as $\mathrm{BP} \geq 140 / 90$ $\mathrm{mmHg}$ or use of antihypertensive treatment) is currently slightly higher in Chile compared to that found in HICs [13].

According to our results, current levels of attainment at each step of the hypertension care cascade are higher in Chile compared to most LMICs [12], while compared to HICs [13], levels of awareness, treatment and control were lower, higher and similar respectively. We found that levels of treated and controlled hypertension significantly increased from 2003 to 2017, while levels of awareness increased only among males between 2003 and 2010. In agreement with global trends, our analyses showed that the proportions of adults reaching each stage of the care cascade were similar to those reported in other HICs and were higher than those in LMICs between 2000 and 2010 [2,12]. Several explanations have been put forward for the global improvement in levels of hypertension awareness, treatment and control, including increases in BP screening at the primary care and community levels, securing better treatment availability, reducing treatment costs, improving treatment adherence and preventing clinical inertia [33]. The GES was launched in Chile in 2005 with a wide marketing strategy and helped to disseminate evidencebased guidelines with simplified recommendations nationwide. In 2014, the law was enforced with an additional regulation called FOFAR, which, for the publicly insured, warranted medicines free-of-charge for hypertension, diabetes and dyslipidaemia. Although we cannot directly assess the impact of these programmes with the ENS data, we can speculate that they have had at least some positive impact through the improvements in treatment and control levels presented here.

\section{Evidence on gender disparities}

Our analyses show no significant difference in hypertension prevalence by gender. However, levels of attainment at each cascade step were higher among females. These gender disparities were also reported among LMICs [12] and HICs [2, 13]. However, the gender gap was wider in Chile than in other HICs. For example, current levels of controlled hypertension were 41 and $26 \%$ higher in relative terms among females in Chile (according to our results) and in HICs, respectively [2]. Potentially these gender disparities arise from higher levels of health care services utilisation among females and from lower long-term adherence to antihypertensive treatment among males [34]. Although gender disparities exist, the trends show some evidence of faster improvements among males. Our analyses show that the Chilean 2010 to 2020 health goal of increasing the level of controlled hypertension by $50 \%$ in relative terms has been achieved among males, but is only at the halfway point among females since the relative increases from 2010 to 2017 were 97 and 24\% for males and females respectively [8].

\section{Implications of lowering BP thresholds}

Using the 2017 data we found that implementing the 2017 ACC/AHA guideline - i.e. lowering the BP threshold from $140 / 90 \mathrm{mmHg}$ to $130 / 80 \mathrm{mmHg}$ - would result 
in 2.3 million more Chilean adults being classified as hypertensive and so be eligible for antihypertensive treatment. This is in addition to the 1.5 million hypertensive adults currently untreated according to the current (JNC 7) guideline. The relative increase of about $55 \%$ in hypertension prevalence as a result of adopting the 2017 ACC/AHA guideline seems to be higher in Chile than those estimated (using similar methods) in the United States (27\%), China (45\%), Spain (42\%) [15, 16], Venezuela (25\%) and Colombia (34\%) [35], but lower than in Peru (130\%) [36]. The definitions used in Venezuela, Colombia and Peru were based on high BP alone $[35,36]$, and so is not strictly comparable with our findings. This new scenario would be a massive challenge for Chile, requiring significant increases in public health expenditure, especially for health-care services and medicines. Implementing the new guideline would potentially increase the absolute number of hypertensives who are aware and on treatment over time. There is a growing debate about the merits of lowering the BP threshold, including concerns about the expected costs of implementation [35, 37].

\section{Strengths and limitations}

One strength of our study is the use of nationally representative health examination survey data, in contrast to the Prospective Urban Rural Epidemiology (PURE) study which covers only a few cities [14], and our use of objective measures which overcome the limitations of self-report data. However, our study has a number of limitations. First, to ensure comparability across the three surveys, we used the average of the first and second $\mathrm{BP}$ readings. Compared to using the average of the second- and third-readings, our approach could have slightly $(<1 \%)$ overestimated hypertension prevalence and underestimated levels of controlled hypertension [38]. Reassuringly, our findings were similar when we repeated our main analyses by taking the average of the second and third readings in the 2010 and 2017 surveys. Second, according to the JNC 7 and 2017 ACC/AHA guidelines, the diagnosis of hypertension should be made at follow-up visits $[9,10]$. Evaluation of BP during a single visit (as done in the ENS surveys) may overestimate the true prevalence as raised BP is not necessarily persistent. According to analyses of Chilean data, a small but statistically significant reduction in hypertension prevalence (1\%) was found when BP measurement was repeated in a follow-up visit [39]. Moreover, the impact of the 'white coat effect' (i.e. transient increase in BP produced by the presence of a healthcare professional) or of 'masked hypertension' (i.e. non-elevated BP in clinical but elevated in ambulatory monitoring) on levels of hypertension could not be estimated in our study.
Third, recall bias could also have impacted on our estimated levels of awareness and treatment. Ascertaining use of antihypertensive treatment based on ATC codes from the medicine inventory could have produced a slight overestimation of prevalence since some medicines can be used for other conditions without the coexistence of hypertension. However, our sensitivity analysis showed that the magnitude of the bias was very small in 2003 and 2017 and only slightly higher in 2010. This suggests a minor recall bias in participants' selfreports or low use of antihypertensive treatments for conditions other than hypertension. The reason behind the slighly higher bias seen in 2010 could be a slightly modification in the question phrasing for ascertaining use of antihypertensive treatment [19]. Fourth, although the same BP monitor was used in each survey, use of different models may have weakened comparability to some extent. Finally, as in other nationally representative health examination surveys, levels of response to the Chilean health survey have decreased over time. However, the current levels of response are comparable to those achieved by other national health examination surveys [40].

Response rates to the surveys were 63, 75 and $67 \%$ for 2003, 2010 and 2017 respectively. The smaller sample size for the 2017 survey resulted in lower precision for the survey estimates and lower statistical power for detecting change over time. Our analyses show that the proportion of female and younger participants in the analytical samples increased over time (data not shown). However, the impact of any differential non-response over time would be reduced by our decision to stratify the analyses by age and gender and by use of nonresponse weighting. It is also worth highlighting the conclusions of previous studies which indicate that the overall response rate for a survey, in and of itself, is not a good indicator of the level of non-response bias [41, 42].

\section{Conclusions}

In conclusion, mean levels of $\mathrm{BP}$ in the untreated and treated populations have declined in Chile during the last 15 years (with the exception of no significant change in mean SBP among females on treatment), while levels of treatment and control among adults with hypertension have increased. The introduction of Universal Access to care for hypertension in 2005 may have accounted at least partly for the rise in levels of treatment and control since 2003. Nevertheless, more population-based interventions (such as increasing taxes on unhealthy foods) and individual level interventions (such as wider use of BP screening among younger males) that address both behavioural risk and protective factors are needed to increase levels of controlled hypertension. Regardless of the hypertension definition, 
innovative and collaborative strategies are needed to improve levels of attainment at each step of the hypertension care cascade, including the promotion of screening and access to care, together with interventions to increase treatment coverage and its adherence, especially among males and high CVD risk populations.

\section{Supplementary information}

Supplementary information accompanies this paper at https://doi.org/10. 1186/s12889-020-09483-X.

Additional file 1: Table S1. Hypertension prevalence, awareness, treatment and control. Chile ENS2003-2010-2017. Table S2. Trends for hypertension prevalence, awareness, treatment and control. Chile ENS2003-2010-2017. Table S3. Trends for hypertension prevalence, awareness, treatment and control according to the definition of mean systolic and diastolic blood pressure (BP). Chile ENS2003-2010-2017.

Figure S1. Prevalence of hypertension (BP $\geq 140 / 90 \mathrm{mmHg}$ or use of antihypertensive treatment) using to define treatment self-reported data (SR) or Anatomical Therapeutic Chemical (ATC) codes from the medicine inventory. Table S4. Blood pressure trends according to treatment status. Chile ENS2003-2010-2017. Table S5. Prevalence, treatment and control of hypertension according to JNC 7 and 2017 ACC/AHA guidelines. Chile ENS2017.

\section{Abbreviations \\ ACC: American College of Cardiology; AHA: American Heart Association; ATC: Anatomical therapeutic chemical; BP: Blood pressure; \\ CVD: Cardiovascular disease; DBP: Diastolic blood pressure; ENS: Encuesta Nacional de Salud (Chilean health survey); GES: Garantías Explícitas en Salud; HICs: High-income countries; JNC 7: Seventh report of the Joint National Committee on Prevention, Detection, Evaluation, and Treatment of High Blood Pressure; LAC: Latin America and Caribbean region; LMICs: Low- and middle- income countries; PURE: Prospective Urban Rural Epidemiology study; SBP: Systolic blood pressure}

\section{Acknowledgements}

The authors thank the interviewers and the nurses, and the participants in the Chilean health surveys.

\section{Authors' contributions}

APS performed the statistical analysis and drafted the manuscript. SS, JSM and MR contributed to the design of the study and revising of the manuscript. PM and CVH critically revised the manuscript. All authors read and approved the final manuscript.

\section{Funding}

ENS 2003, 2010 and 2017 were funded by the Chilean Ministry of Health. Paula Margozzini was funded to conduct ENS2003, ENS2010 and ENS2017; Álvaro Passi-Solar was funded to conduct ENS2017. The funder had no role in the data analysis, data interpretation, writing, or in the decision to submit the paper for publication.

\section{Availability of data and materials}

The datasets generated and/or analysed during the current study are available in the Chilean Ministry of Health webpage: Departamento de Epidemiología, Ministerio de Salud de Chile, Encuesta Nacional de Salud, 2016-2017 at http://epi.minsal.cl/bases-de-datos/

\section{Ethics approval and consent to participate}

The study protocol and ethical consent forms were approved by the ethics committee of the Pontificia Universidad Católica de Chile (PUC) and the Chilean Ministry of Health (ENS 2003: number could not be retrieved; 2010: 09-113; 2017: 16-019). Persons selected for inclusion provided informed and signed consent before participation.

\section{Consent for publication}

Not applicable.

\section{Competing interests}

The authors declare that they have no competing interests.

\section{Author details}

${ }^{1}$ Research Department of Epidemiology and Public Health, University College London, 1-19 Torrington Place, London WC1E 6BT, UK. Department of Public Health, School of Medicine, Pontificia Universidad Católica de Chile, Diagonal Paraguay 362, CP 88330077 Santiago, Chile.

Received: 18 February 2020 Accepted: 31 August 2020

Published online: 14 September 2020

\section{References}

1. NCD Risk Factor Collaboration (NCD-RisC). Worldwide trends in blood pressure from 1975 to 2015: a pooled analysis of 1479 population-based measurement studies with 19.1 million participants. Lancet. 2017;389:37-55.

2. Mills KT, Bundy JD, Kelly TN, Reed JE, Kearney PM, Reynolds K, et al. Global. disparities of hypertension prevalence and control: a systematic analysis of population-based studies from 90 countries. Circulation. 2016;134:441-50.

3. Ministerio Salud, Chile. Causas de muerte 2010-2017 [Causes of deaths 2010-2017]. 2017. https://repositoriodeis.minsal.cl/DatosAbiertos/Vitales/ DEF_2010-2017.rar.

4. OECD. Health at a glance 2019: OECD Indicators; 2019. https://doi.org/10. 1787/4dd50c09-en.

5. Florenzano Urzua R, Roessler E, Scharazer J, Soto I, Cantú AM. Permanencia en tratamiento antihipertensivo: comparación de dos sistemas de seguimiento. Perseverance in antihypertensive therapy: comparison of 2 follow-up systems. Bol Oficina Sanit Panam. 1981;91:428-40.

6. Ministerio de Desarrollo Social, Chile. National socioeconomic characterization survey (CASEN) 2015: health results 2015. http:// observatorio.ministeriodesarrollosocial.gob.cl/casen-multidimensional/casen/ docs/CASEN_2015_Resultados_salud.pdf.

7. Ministerio Salud, Chile. Guía Clínica de Hipertensión Arterial Primaria o esencial en personas de 15 años y más [Clinical guidelines for primary or essential arterial hypertension in people aged 15 years and over]. 2010. http://epi.minsal.cl.

8. Ministerio Salud, Chile. Objetivos Sanitarios 2011-2020 [Health objectives 2011-2020]. 2016. http://www.salud-e.cl/biblioteca/estrategia-sanitariachilena/objetivos-sanitarios-2011-2020/.

9. Whelton PK, Carey RM, Aronow WS, Casey DE, Collins KJ, Dennison Himmelfarb C, et al. 2017 ACC/AHA/AAPA/ABC/ACPM/AGS/APhA/ASH/ ASPC/NMA/PCNA guideline for the prevention, detection, evaluation, and management of high blood pressure in adults: a report of the American College of Cardiology/American Heart Association task force on clinical practice guidelines. Hypertension. 2018;71:e13-e115. https://doi.org/10. 1161/HYP.0000000000000065.

10. Chobanian AV, Bakris GL, Black HR, Cushman WC, Green LA, Izzo JL, et al. The seventh report of the joint national committee on prevention, detection, evaluation, and treatment of high blood pressure: the JNC 7 report. JAMA. 2003;289:2560-72.

11. SPRINT Research Group, Wright JT, Williamson JD, Whelton PK, Snyder JK, Sink KM, et al. A randomized trial of intensive versus standard bloodpressure control. N Engl J Med. 2015;373:2103-16.

12. Geldsetzer P, Manne-Goehler J, Marcus M-E, Ebert C, Zhumadilov Z, Wesseh $\mathrm{CS}$, et al. The state of hypertension care in 44 low-income and middleincome countries: a cross-sectional study of nationally representative individual-level data from 1·1 million adults. Lancet. 2019;394:652-62.

13. Zhou B, Danaei G, Stevens GA, Bixby H, Taddei C, Carrillo-Larco RM. Longterm and recent trends in hypertension awareness, treatment, and contro in 12 high-income countries: an analysis of 123 nationally representative surveys. Lancet. 2019;394:639-51.

14. Lamelas P, Diaz R, Orlandini A, Avezum A, Oliveira G, Mattos A, et al. Prevalence, awareness, treatment and control of hypertension in rural and urban communities in Latin American countries. J Hypertens. 2019;37:181321.

15. Khera R, Lu Y, Lu J, Saxena A, Nasir K, Jiang L, et al. Impact of 2017 ACC/ AHA guidelines on prevalence of hypertension and eligibility for antihypertensive treatment in United States and China: nationally representative cross sectional study. BMJ. 2018;362:k2357.

16. Gijón-Conde T, Sánchez-Martínez M, Graciani A, Cruz JJ, López-García E, Ortolá $\mathrm{R}$, et al. Impact of the European and American guidelines on 
hypertension prevalence, treatment, and cardiometabolic goals. J Hypertens. 2019;37:1393-400.

17. Ministerio Salud, Chile. Chilean National quality of life and health survey 2000, GHDx. 2010. http://ghdx.healthdata.org/record/chile-national-qualitylife-and-health-survey-2000.

18. Kish L. Survey Sampling. New York: Wiley; 1965.

19. Ministerio Salud, Chile. Chilean National Health Survey: questionnaires, datasets, and related documentation [Encuesta nacional de salud (ENS): Contenido informativo descargable]. EPI - Departamento de Epidemiologia http://epi.minsal.cl/encuesta-ens-descargable/. Accessed 29 Jun 2020.

20. WHO-Collaborating Centre for Drug Statistics Methodology. Guidelines for ATC classification and DDD assignment 2019. 2018. https://www.whocc.no/ filearchive/publications/2019_guidelines_web.pdf.

21. Schulze MB, Kroke A, Bergmann MM, Boeing H. Differences of blood pressure estimates between consecutive measurements on one occasion: implications for inter-study comparability of epidemiologic studies. Eur J Epidemiol. 2000;16:891-8.

22. Instituto Nacional de Estadísticas (INE). Actualización de población 20022012 y proyecciones 2013-2020. 2017. http://www.ine.cl/estadisticas/ demograficas-y-vitales.

23. NCD Risk Factor Collaboration (NCD-RisC). Trends in adult body-mass index in 200 countries from 1975 to 2014: a pooled analysis of 1698 populationbased measurement studies with 19.2 million participants. Lancet. 2016;387: 1377-96.

24. Margozzini P, Salud PÁEN. ENS 2016-2017: un aporte a la planificación sanitaria y políticas públicas en Chile [National Health Survey, ENS 20162017: a contribution to health planning and public policies in Chile]. ARS MEDICA Rev Cienc Méd. 2018;43:30-4.

25. Zhou B, Bentham J, Di Cesare M, Bixby H, Danaei G, Hajifathalian K, et al. Contributions of mean and shape of blood pressure distribution to worldwide trends and variations in raised blood pressure: a pooled analysis of 1018 population-based measurement studies with 88.6 million participants. Int J Epidemiol. 2018;47:872-883i.

26. Leng B, Jin Y, Li G, Chen L, Jin N. Socioeconomic status and hypertension: a meta-analysis. J Hypertens. 2015;33:221-9.

27. Guerrero-Ahumada A. Socioeconomic inequalities in blood pressure in Chilean adults. Doctoral thesis,. School of Medicine, University College London. Doctoral. UCL (University College London; 2017. http://discovery. ucl.ac.uk/1535336/.

28. Ministerio Desarrollo Social, Chile. National socioeconomic characterization survey (CASEN) 2017: results. Observatorio social 2017. http://observatorio. ministeriodesarrollosocial.gob.cl/casen-multidimensional/casen/casen_2017. php.

29. Ministerio Salud, Chile. Encuesta Nacional de Salud 2016-2017: Segunda entrega de resultados [Chilean National Health Survey 2016-2017: results, second report]. 2018. https://www.minsal.cl/wp-content/uploads/2018/01/2Resultados-ENS_MINSAL_31_01_2018.pdf.

30. Colón-Ramos U, Monge-Rojas R, Campos H. Impact of WHO recommendations to eliminate industrial trans-fatty acids from the food supply in Latin America and the Caribbean. Health Policy Plan. 2014;29:52941.

31. Corvalán C, Reyes M, Garmendia ML, Uauy R. Structural responses to the obesity and non-communicable diseases epidemic: update on the Chilean law of food labelling and advertising. Obes Rev. 2019;20:367-74.

32. Bambs C, Bravo-Sagua R, Margozzini P, Lavandero S. Science and health policies to tackle chronic diseases in Chile. Trends Endocrinol Metab. 2020; 31:67-70.

33. Adler AJ, Prabhakaran D, Bovet P, Kazi DS, Mancia G, Mungal-Singh V, et al. Reducing cardiovascular mortality through prevention and management of raised blood pressure: a world heart federation roadmap. Glob Heart. 2015; 10:111-22.

34. Abegaz TM, Shehab A, Gebreyohannes EA, Bhagavathula AS, Elnour AA. Nonadherence to antihypertensive drugs. Medicine. 2017;96:e5641. https:// doi.org/10.1097/MD.0000000000005641.

35. López-Jaramillo P, López-López J, Forero-Trillos MF, Rueda-Quijano SM, Camacho PA, Esmeral-Ordoñez D, et al. Will the new figures from the AHA/ ACC guidelines on the definition and treatment of hypertension in Latin America have an impact? [iRepercutirán las nuevas cifras de las guías AHA/ ACC en la definición y manejo de la hipertensión en Latinoamérica?]. Hipertens Riesgo Vasc. 2020;37:33-8.
36. Hernández-Vásquez A, Rojas-Roque C, Santero M, Ruiz-Maza JC, CasasBendezú M, Miranda JJ. Changes in the prevalence of hypertension in Peru using the new guideline of the American College of Cardiology. Rev Méd Chile. 2019;147:545-56.

37. Ioannidis JPA. Diagnosis and treatment of hypertension in the 2017 ACC/ AHA guidelines and in the real world. JAMA. 2018;319:115-6.

38. Handler J, Zhao Y, Egan BM. Impact of the number of blood pressure measurements on blood pressure classification in US adults: NHANES 19992008. J Clin Hypertens. 2012;14:751-9.

39. Montero J, Mansilla C, Margozzini P. [Effects of incorporating additional blood pressure measurements during The National Health Survey in Chile]. Rev Med Chil 2016;144:285-290.

40. Mindell JS, Giampaoli S, Goesswald A, Kamtsiuris P, Mann C, Männistö S, et al. Sample selection, recruitment and participation rates in health examination surveys in Europe--experience from seven national surveys. BMC Med Res Methodol. 2015;15:78.

41. Czajka JL, Beyler A. Declining response rates in Federal Surveys: trends and implications. Washington, DC: Mathematica Policy Research; 2016. https:// www.mathematica.org/our-publications-and-findings/publications/decliningresponse-rates-in-federal-surveys-trends-and-implications-background-paper.

42. Groves RM, Peytcheva E. The impact of nonresponse rates on nonresponse bias: a meta-analysis. Public Opin Q. 2008;72:167-89.

\section{Publisher's Note}

Springer Nature remains neutral with regard to jurisdictional claims in published maps and institutional affiliations.

\section{Ready to submit your research? Choose BMC and benefit from:}

- fast, convenient online submission

- thorough peer review by experienced researchers in your field

- rapid publication on acceptance

- support for research data, including large and complex data types

- gold Open Access which fosters wider collaboration and increased citations

- maximum visibility for your research: over $100 \mathrm{M}$ website views per year

At $\mathrm{BMC}$, research is always in progress.

Learn more biomedcentral.com/submissions 